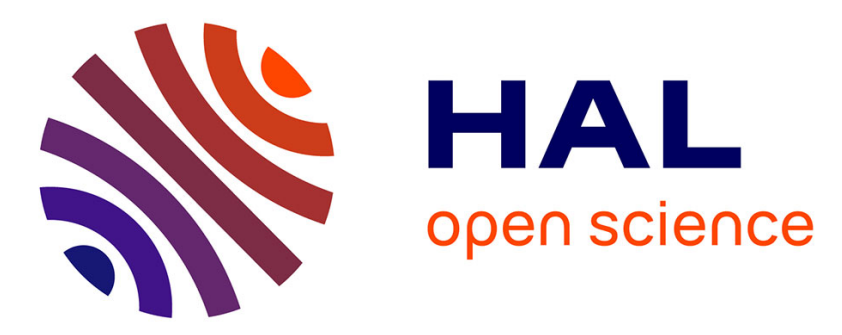

\title{
A microcantilever chemical sensors optimization by taking into account losses
}

\author{
Frédéric Lochon, Isabelle Dufour, Dominique Rebiere
}

\section{To cite this version:}

Frédéric Lochon, Isabelle Dufour, Dominique Rebiere. A microcantilever chemical sensors optimization by taking into account losses. Sensors and Actuators B: Chemical, 2006, 118, pp.292-296. hal00203738

\section{HAL Id: hal-00203738 \\ https://hal.science/hal-00203738}

Submitted on 13 Nov 2014

HAL is a multi-disciplinary open access archive for the deposit and dissemination of scientific research documents, whether they are published or not. The documents may come from teaching and research institutions in France or abroad, or from public or private research centers.
L'archive ouverte pluridisciplinaire HAL, est destinée au dépôt et à la diffusion de documents scientifiques de niveau recherche, publiés ou non, émanant des établissements d'enseignement et de recherche français ou étrangers, des laboratoires publics ou privés. 


\title{
A MICROCANTILEVER CHEMICAL SENSORS OPTIMIZATION BY TAKING INTO ACCOUNT LOSSES
}

\author{
Frédéric Lochon $^{* 1}$, Isabelle Dufour ${ }^{1}$, Dominique Rebière ${ }^{1}$ \\ ${ }^{1}$ Laboratoire IXL - CNRS UMR 5818 - ENSEIRB - Université Bordeaux 1 \\ 351 cours de la libération 33405 Talence - France \\ lochon@ixl.fr, Tel: +33 54000 2881, Fax: +33 556371545
}

\begin{abstract}
The current trend in increasing microcantilever resonant frequencies leads to relatively low quality factors for microcantilevers resonating in a gas medium. In order to increase the quality factor of such high-frequency microcantilevers, an approach that takes into account the different types of losses is provided to specify appropriate values of microcantilever aspect ratios (length-to-thickness, width-tothickness). Conventional values of aspect ratios result in low quality factors, while those proposed here lead to slightly higher values of quality factor.
\end{abstract}

Keywords: Microcantilever; chemical sensor; quality factor; losses; aspect ratio

\section{Introduction}

In order to design a very sensitive microcantilever-based chemical sensor, it is required to use highfrequency devices. Indeed, the sensitivity of such sensors is proportional to the resonant frequency. Moreover, to achieve a minimal limit of detection, high quality factors are preferable because they (a) increase the sharpness of the resonance peak and, thus, the frequency shift measurement accuracy, and (b) result in lower short-term noise in oscillator configurations.

A theoretical approach is proposed to show the importance of taking into account different losses when designing a microcantilever-based sensor. The importance of increasing the resonant frequency is first presented and the four dominant losses that occur in a viscous medium are then detailed and analytical forms of equivalent quality factors are given. The relevance of taking into account each loss is detailed and illustrated. Then, the existence of an optimum quality factor for a given microcantilever length is illustrated and optimum aspect ratios (length to width, length to thickness) are presented. A discussion then follows which compares conventional aspect ratios with fully optimum and nearly optimum aspect ratios. A conclusion is then made about the proposed aspect ratio expressions.

\section{Theoretical study}

\subsection{Assumptions}

This study is limited to uniform parallelepiped shaped microcantilevers with a negligible sensitive coating Young's modulus.

The microcantilever vibration amplitude is considered far smaller than any dimension to neglect non linear effects.

\subsection{Sensor sensitivity}

The resonant frequency $f_{n}$ of a parallelepiped shaped microcantilever with a sensitive coating deposited on its top (Figure 1 ) is given by [1]:

$$
f_{n}=\frac{1}{4 \pi}\left(\frac{\lambda_{n}}{L_{1}}\right)^{2} \sqrt{\frac{\hat{E}_{1} h_{1}^{3}}{3\left(\rho_{1} h_{1}+\rho_{2} h_{2}\right)}}
$$

where $\lambda_{n}$ is a parameter depending on the mode order, $L_{1}$ is the microcantilever length, $\hat{E}_{1}$ is the effective microcantilever Young's modulus, $h_{1}$ and $h_{2}$ are the microcantilever and sensitive coating thicknesses respectively, and $\rho_{1}$ and $\rho_{2}$ are the microcantilever and sensitive coating mass densities respectively. 
From equation (1) it can be seen that the resonant frequency is inversely proportional to the dimensions if we do a geometric contraction by keeping constant the aspect ratios (length to thickness: $L_{1} / h_{1}$, length to width $L_{1} / b_{1}$, coating thickness to cantilever thickness $h_{2} / h_{1}$ ).

The sensitivity $S$ of a sensor exposed to a gas concentration $C_{g}$ is given by:

$$
S=\frac{\Delta f_{n}}{C_{g}}=\frac{1}{2} f_{n} K \frac{r}{\rho_{1}+\rho_{2} r}
$$

where $\Delta f_{n}$ is the frequency shift due to gas sorption, $K$ the partition coefficient of the sensitive coating - gas couple and $r=h_{2} / h_{1}$.

Thus, high resonant frequency devices will have high sensitivity. But in order to have a low limit of detection, a high sensitivity is not sufficient: the noise has to be taken into account.

\subsection{About losses}

The quality factor, a key parameter for the accuracy of the measurement, expresses the losses influence: low-loss microcantilevers will have a high quality factor.

For most microcantilevers resonating in vacuum, the quality factor is determined by thermoelastic losses and support losses. But when used in air, these cantilevers can have a much lower quality factor because of the viscous losses due to the surrounding fluid and because an acoustic radiation may occur for wide cantilevers [2].

To evaluate the global quality factor, each loss is first studied separately. Then the global quality factor is calculated using:

$$
\frac{1}{Q_{\text {global }}}=\frac{1}{Q_{1}}+\frac{1}{Q_{2}}+\ldots+\frac{1}{Q_{n}}
$$

This approach is fully valid for low loss microcantilevers and thus it can be applied to determine how to minimize losses.

\subsection{Viscous losses}

When vibrating in a fluid, a microcantilever is perturbed by viscosity and mass density of the environment. A general theoretical model describing viscous losses has been established by Sader [3].

For microcantilevers with a rectangular cross section, the equivalent quality factor associated with viscous losses can be analytically expressed:

$$
Q_{\text {viscous }}=\frac{\frac{4 \rho_{1} h_{1}}{\pi \rho_{0} b_{1}}+\Gamma_{r}\left(\omega_{n}\right)}{\Gamma_{i}\left(\omega_{n}\right)}
$$

where $\omega_{n}$ is the resonant pulsation, $\rho_{0}$ is the density of the fluid, and $\Gamma_{r}$ and $\Gamma_{i}$ are the real and imaginary components of the hydrodynamic function $\Gamma\left(\omega_{n}\right)$ of the microcantilever.

Sader has also proposed an approximate analytical expression of the hydrodynamic function for a wide range of Reynolds number [3].

Using equation (4), it can be seen that viscous losses are important for high values of $L_{1} / h_{1}$ or for very narrow microcantilevers.

\subsection{Support losses}


To obtain equation (1), it has been supposed an infinitely rigid support. In fact, the vibration of the microcantilever produces a mechanical work on the support. This mechanical work generates an elastic wave into the support. The generated wave power is lost by propagation.

Hao et al. have proposed an analytical approach to quantify these losses [4]. The associated equivalent quality factor for a silicon based microcantilever is given by:

$$
Q_{\text {support }}=3.97 \frac{1}{\left(\chi_{n} \lambda_{n}\right)^{2}}\left(\frac{L_{1}}{h_{1}}\right)^{3}
$$

with:

$$
\chi_{n}=\frac{\sin \left(\lambda_{n}\right)-\sinh \left(\lambda_{n}\right)}{\cos \left(\lambda_{n}\right)+\cosh \left(\lambda_{n}\right)}
$$

It can be seen from equation (5) that support losses are important for low values of $L_{1} / h_{1}$.

\subsection{Acoustic losses}

The vibration of the microcantilever in the fluid creates an acoustic pressure which propagates into the fluid. The evaluation of this acoustic radiation in the case of a microcantilever with a rectangular cross section is not trivial. By approximating the rectangular cross section with an elliptical cross section, Blake has obtained an approximate expression for the radiated power [5]:

$$
P_{\omega}=\frac{\pi \rho_{0} c_{0}\left(k_{0} b_{1}\right)^{4}}{512} \int_{\theta=0}^{\pi} \sin ^{3} \theta\left|\bar{U}_{\omega}\left(k_{0} \cos \theta\right)\right|^{2} d \theta
$$

where $c_{0}$ is the speed of sound in the fluid, $k_{0}=\omega / c_{0}$ is the wavenumber in the fluid and $\bar{U}_{\omega}(v)$ is given by:

$$
\bar{U}_{\omega}(v)=\int_{0}^{4} U_{\omega}(x) e^{-j x v} d x
$$

with $U_{\omega}(x)$ the microcantilever velocity along the $z$ axis at pulsation $\omega$.

To calculate the microcantilever velocity we can approximate the microcantilever mode shape in presence of low losses to the microcantilever mode shape without losses. It then comes:

$$
U_{\omega_{n}}=j \omega_{n} w\left(x, \omega_{n}\right)
$$

with:

$$
w\left(x, \omega_{n}\right)=A \Phi_{\text {vac }}(x)
$$

where $A$ is the oscillation amplitude and $\Phi_{\text {vac }}(x)$ the mode shape of the microcantilever given by:

$$
\Phi_{\text {vac }}(x)=\cos \left(\frac{\lambda_{n} x}{L_{1}}\right)-\cosh \left(\frac{\lambda_{n} x}{L_{1}}\right)+\frac{\cos \left(\lambda_{n}\right)+\cosh \left(\lambda_{n}\right)}{\sin \left(\lambda_{n}\right)+\sinh \left(\lambda_{n}\right)}\left[\sinh \left(\frac{\lambda_{n} x}{L_{1}}\right)-\sin \left(\frac{\lambda_{n} x}{L_{1}}\right)\right]
$$

Using (7) and (8) it then comes:

$$
P_{\omega_{n}}=\frac{\pi \rho_{0} c_{0}\left(k_{0} b_{1}\right)^{4} \omega_{n}^{2}}{512} \int_{\theta=0}^{\pi} \sin ^{3} \theta\left|I_{k_{0} \cos \theta}\right|^{2} d \theta
$$

with:

$$
I_{v}=\int_{x=0}^{4} w\left(x, \omega_{n}\right) e^{-j v x} d x
$$

The radiated energy during one period is given by: 


$$
W_{\text {radiated }}=\frac{P_{\omega_{n}}}{2 \pi \omega_{n}}
$$

The equivalent quality factor associated with acoustic radiation can be calculated using [4]:

$$
Q_{\text {rad }}=2 \pi \frac{W_{\text {cantilever }}}{W_{\text {radiated }}}
$$

with:

$$
W_{\text {cantilever }}=\frac{1}{2} \mu_{12} \omega_{n}^{2} \int_{x=0}^{4} w^{2}\left(x, \omega_{n}\right) d x
$$

where $\mu_{12}=b_{1}\left(\rho_{1} h_{1}+\rho_{2} h_{2}\right)$ is the linear mass of the microcantilever with the sensitive coating.

Using equations (9) to (16), it then comes:

$$
Q_{r a d}=\frac{1024 \pi \mu_{12} \omega_{n} \int_{0}^{L} \Phi_{v a c}^{2} d x}{\rho_{0} c_{0} k_{0}^{4} b_{1}^{4} \int_{0}^{\pi} \sin ^{3} \theta\left|\int_{0}^{L} \Phi_{v a c} e^{-j \times k_{0} \cos \theta} d x\right|^{2} d \theta}
$$

By using numerical calculations of (17) it can be seen that acoustic radiation becomes important for wide microcantilevers and for "acoustically long microcantilevers". The term "acoustically long microcantilevers" refers to cantilevers for which the structural wavelength $\left(L_{1} / \lambda_{n}\right)$ is comparable to the acoustic wavelength $\left(\lambda=2 \pi / k_{0}\right)$ in the fluid.

\subsection{Thermoelastic losses}

Thermoelastic losses are caused by the microcantilever material heating due to vibration. Lifshitz et al. have expressed analytically the equivalent quality factor associated with thermoelastic losses [6]:

$$
Q_{\text {thermo }}=\frac{C_{p_{1}} \rho_{1}}{6 \hat{E}_{1} \alpha_{1}^{2} T} \frac{\zeta^{2}}{1-\frac{1}{\zeta} \frac{\sinh (\zeta)+\sin (\zeta)}{\cosh (\zeta)+\cos (\zeta)}}
$$

with:

$$
\zeta=h_{1} \sqrt{\frac{\omega_{n} \rho_{1} C_{p_{1}}}{2 \kappa}}
$$

where $C_{p_{1}}, \alpha_{1}, T, \kappa$, are the heat capacity, the thermal expansion coefficient, the temperature, and the thermal conductivity of the microcantilever material, respectively, and $\omega_{n}$ is the microcantilever resonant pulsation.

From equation (18) it can be seen that thermoelastic losses are maximum for $\zeta \cong 2.2246$. At this maximum loss, the thermoelastic quality factor for a silicon made microcantilever at room temperature is bigger than $10^{4}$.

\section{Discussion on the total quality factor}

The combination of all the losses shows that no general trend can be given to minimize all losses at the same time: an optimum value should exists. In fact, when combining the losses, it comes that optimal aspect ratios can be found for a given length (Figure 2).

Indeed, the thickness can be adjusted to equilibrate viscous losses and support losses (Figure 3), while the width can be adjusted to equilibrate viscous losses and acoustic losses (Figure 4). 
Because of the approximations in the evaluation of the quality factor associated with acoustic losses and because of the analytical expression forms, no exact analytical equations can be given to choose the aspect ratios $\left(L_{1} / h_{1}, L_{1} / b_{1}\right)$. However, by determining the optimal width and thickness for a given microcantilever length, it is possible to observe that using $L_{1} / h_{1}=20$ and $L_{1} / b_{1}=3$ is a simple rule to obtain an almost optimal quality factor.

From figure 2, it can be seen that using conventional aspect ratios $\left(L_{1} / h_{1}>50, L_{1} / b_{1}>10\right)$ implies that viscous losses are dominant and thus sufficient to calculate the quality factor. But in that case, the quality factor can be much lower while the resonant frequency remains low because of a high $L_{1} / h_{1}$ ratio. A comparison between different aspect ratios is made in table 1.

It can be seen that, even if the proposed aspect ratios are not fully optimal, they allow to increase significantly both the quality factor and the resonant frequency compared to conventional aspect ratios.

Moreover, approximate relationships between the length and optimal width and thickness can be found in order to have even higher quality factors and resonant frequencies. With a numerical resolution (as presented in Figure 2 for one length), the optimum width (Figure 5) and thickness (Figure 6) have been obtained for microcantilever lengths between $10 \mu \mathrm{m}$ and $1 \mathrm{~mm}$.

Using these optimum dimensions, two fitted expressions are proposed to obtain more precise ratios. The fitted expressions for the ratio length to optimum width (20) and length to optimum thickness (21), plotted on figures 5 and 6 , are given by:

$$
\begin{aligned}
& \frac{L_{1}}{b_{\text {oppinum }}}=2.9+1.6 \tanh \left(\log _{10}\left(\frac{L_{1}}{L_{b}}\right)\right) \\
& \frac{L_{1}}{h_{\text {oppinum }}}=13+3.4 \tanh \left(\log _{10}\left(\frac{L_{1}}{L_{h}}\right)\right)
\end{aligned}
$$

with $L_{b}=10^{-4} \mathrm{~m}$ and $L_{h}=10^{-3.9} \mathrm{~m}$.

The fitted expressions (20) and (21) should be used with care because they have been established for lengths only from $10 \mu \mathrm{m}$ to $1 \mathrm{~mm}$. Moreover, as said previously, the actual quality factor may be different due to approximations in the calculation of the acoustic losses.

\section{Conclusion}

The method, which takes into account all loses in microcantilever, presented here can help choosing microcantilever dimensions to increase the sensitivity, because of a frequency increase, and to reduce the limit of detection, because of a quality factor optimization. The aspect ratios can be chosen by using a simple rule $\left(L_{1} / h_{1}=20, L_{1} / b_{1}=3\right)$, to obtain a nearly optimum quality factor, or by using the fitted expressions (20) and (21), to obtain a fully optimum quality factor. In both the nearly optimum and fully optimum cases, the resonant frequency, which is linked to the sensitivity, the quality factor, which impacts the limit of detection, and the top surface $\left(L_{1}, b_{1}\right)$, which is usually used for coating deposition and/or movement detection, are all increased. Such optimized microcantilever could be very interesting in terms of performance.

This work has not taken into account losses that can occur in the sensitive coating (for example viscoelastic losses when using polymers as sensitive coatings). These aspect ratios can be significantly modified when using high loss sensitive coating (thick viscoelastic materials). However, if analytical expressions can be found for these losses, a similar work may be conducted to possibly find new aspect ratios.

These proposed aspect ratios are no longer valid in water, but similar work can be done since the equations can be applied on any fluid as long as viscosity and mass density are known. 


\section{ACKNOWLEDGEMENTS}

This work was sponsored in part by the French Agency for Environment and Energy Management (ADEME) and the "Région Aquitaine".

\section{REFERENCES}

[1] R. D. Blevins, Formulas for natural frequency and mode shape, Van Nostrand Reinhold Company, 1978, p 108.

[2] D. Lange, C. Hagleitner, A. Hierlemann, O. Brand, H. Baltes, Complementary metal oxide semiconductor cantilever arrays on a single chip: mass-sensitive detection of volatile organic compounds, Analytical Chemistry, 74 (2002), pp 3084-3095.

[3] J. E. Sader, Frequency response of cantilever beams immersed in viscous fluids with applications to the atomic force microscope, Journal of applied physics, 84 (1998), pp 64-76.

[4] Z. Hao, A. Erbil, F. Ayazi, An analytical model for support loss in micromachined beam resonators with in-plane flexural vibrations, Sensors and Actuators A, 109 (2003), pp 156-164.

[5] W. K. Blake, The radiation from free-free beams in air and in water, Journal of Sound and Vibration, 33 (1974), pp 427-450.

[6] R. Lifshitz, M. L. Roukes, Thermoelastic damping in micro- and nanomechanical systems, Physical Review B, 61 (2000), pp 5600-5609.

\section{BIOGRAPHIES}

Frédéric LOCHON received in 2003 the 'Diplôme d'Etudes Approfondies' in electronics and the 'Diplôme d'Ingénieur' in electronics from the 'Ecole Nationale Supérieure d'Électronique d'Informatique et de Radiocommunication de Bordeaux'. He is currently a Ph. D. student at the IXL Microelectronic Laboratory and is working on microcantilever used for volatile organic compounds detection.

Isabelle DUFOUR received the 'Agrégation de Sciences Physiques (option physique appliquée)' in 1989, her Ph. D. degree from the University of Paris Sud Orsay in 1993 (on the use of magnetic sensors for non destructive testing) and her 'HDR', accreditation to supervise research, on the modeling of microactuators in 2000. She is presently a researcher for the CNRS at the IXL Microelectronic Laboratory. Her research is now focused on chemical microsensors using moving structures.

Dominique REBIĖRE received the 'Maîtrise d'Électronique Électrotechnique Automatique', the 'Diplôme d'Études Approfondies' in Electronics and a Ph. D. from Bordeaux 1 University, France, in 1987, 1988 and 1992, respectively. He has been involved in research surface acoustic wave sensors since 1989 at Bordeaux 1 University, IXL Microelectronic Laboratory and is professor at Bordeaux 1 University in Electronic Engineering. 
Preprint - Sensors and Actuators B, Vol 118, 2006, pp. 292-296. (doi: 10.1016/j.snb.2006.04.034).

Table 1: Comparison between different aspect ratios for 3 microcantilever lengths

\begin{tabular}{|c|c|c|c|c|c|c|c|}
\hline $\begin{array}{c}\text { Length } \\
(\mu \mathrm{m})\end{array}$ & $\begin{array}{c}\text { Aspect ratio } \\
\text { type }\end{array}$ & $\begin{array}{c}\text { Width } \\
(\mu \mathrm{m})\end{array}$ & $\begin{array}{c}\text { Thickness } \\
(\mu \mathrm{m})\end{array}$ & $\begin{array}{c}\text { Ratio length } \\
\text { to width }\end{array}$ & $\begin{array}{c}\text { Ratio length } \\
\text { to thickness }\end{array}$ & $\begin{array}{c}\text { Quality } \\
\text { factor }\end{array}$ & $\begin{array}{c}\text { Resonant } \\
\text { frequency }(\mathrm{kHz})\end{array}$ \\
\hline \multirow{3}{*}{10} & Optimum & 6.6 & 1 & 1.515 & 10 & 641 & 12000 \\
\cline { 2 - 8 } & Proposed & $\mathbf{3 . 3 3}$ & $\mathbf{0 . 5}$ & $\mathbf{3}$ & $\mathbf{2 0}$ & $\mathbf{3 0 0}$ & $\mathbf{6 1 0 0}$ \\
\cline { 2 - 8 } & Conventional & 1 & 0.2 & 10 & 50 & 44.9 & 2400 \\
\hline \multirow{3}{*}{100} & Optimum & 37 & 7.7 & 2.703 & 12.99 & 1290 & 960 \\
\cline { 2 - 8 } & Proposed & $\mathbf{3 3 . 3 3}$ & $\mathbf{5}$ & $\mathbf{3}$ & $\mathbf{2 0}$ & $\mathbf{9 6 8}$ & $\mathbf{6 2 0}$ \\
\cline { 2 - 8 } & Conventional & 10 & 2 & 10 & 50 & 219 & 240 \\
\hline \multirow{3}{*}{1000} & Optimum & 260 & 65 & 3.846 & 15.38 & 2460 & 78 \\
\cline { 2 - 8 } & Proposed & $\mathbf{3 3 3 . 3 3}$ & $\mathbf{5 0}$ & $\mathbf{3}$ & $\mathbf{2 0}$ & $\mathbf{2 1 6 0}$ & $\mathbf{6 2}$ \\
\cline { 2 - 8 } & Conventional & 100 & 20 & 10 & 50 & 813 & 24 \\
\hline
\end{tabular}


Preprint - Sensors and Actuators B, Vol 118, 2006, pp. 292-296. (doi: 10.1016/j.snb.2006.04.034).

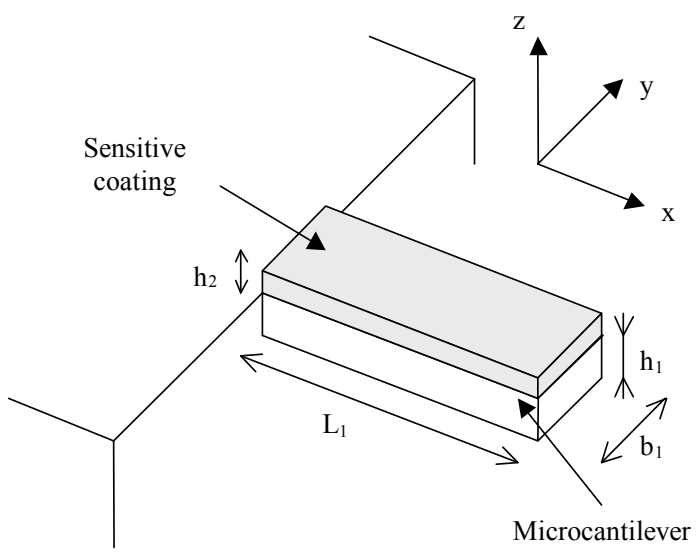

Figure 1: Geometry of the microcantilever and its sensitive coating 
Preprint - Sensors and Actuators B, Vol 118, 2006, pp. 292-296. (doi: 10.1016/j.snb.2006.04.034).

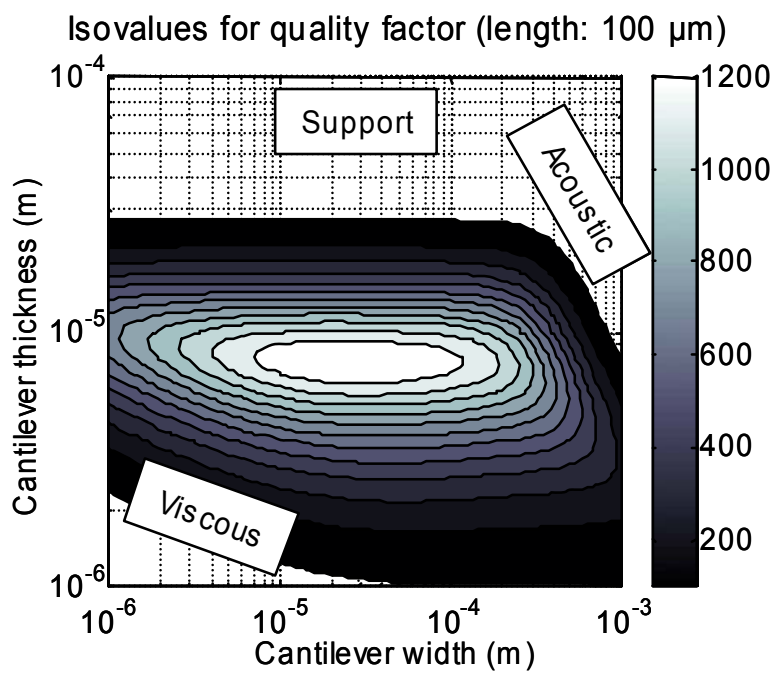

Figure 2: Total quality factor and dominant losses for a $100 \mu \mathrm{m}$ long microcantilever as a function of the microcantilever width and thickness 
Preprint - Sensors and Actuators B, Vol 118, 2006, pp. 292-296. (doi: 10.1016/j.snb.2006.04.034).

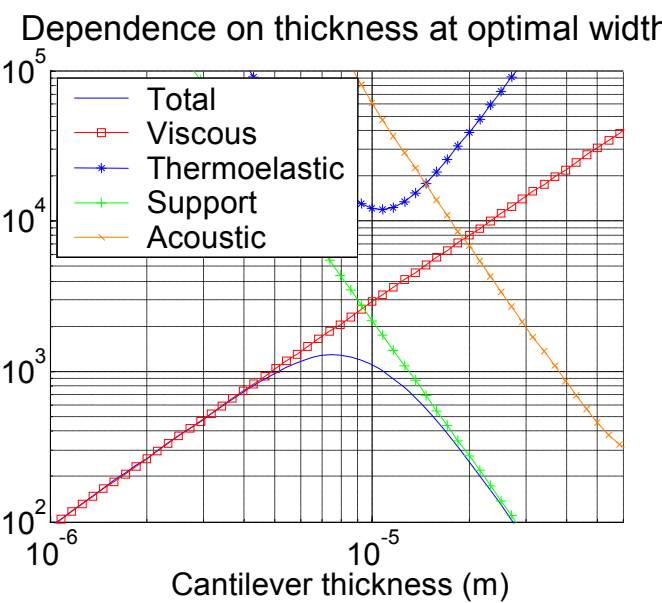

Figure 3: Quality factors (log scale) at the optimal width $(37 \mu \mathrm{m})$ for a $100 \mu \mathrm{m}$ long microcantilever as a function of the thickness (log scale) 
Preprint - Sensors and Actuators B, Vol 118, 2006, pp. 292-296. (doi: 10.1016/j.snb.2006.04.034).

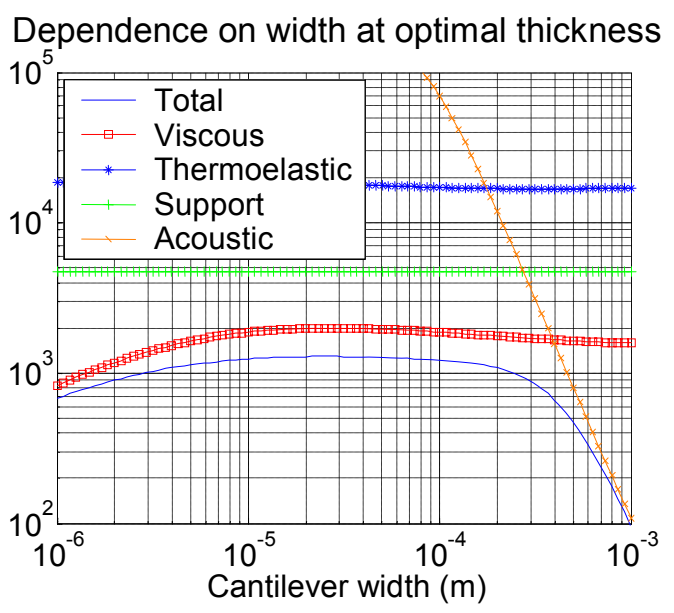

Figure 4: Quality factors (log scale) at the optimal thickness (7.7 $\mu \mathrm{m})$ for a $100 \mu \mathrm{m}$ long microcantilever as a function of the width (log scale) 
Preprint - Sensors and Actuators B, Vol 118, 2006, pp. 292-296. (doi: 10.1016/j.snb.2006.04.034).

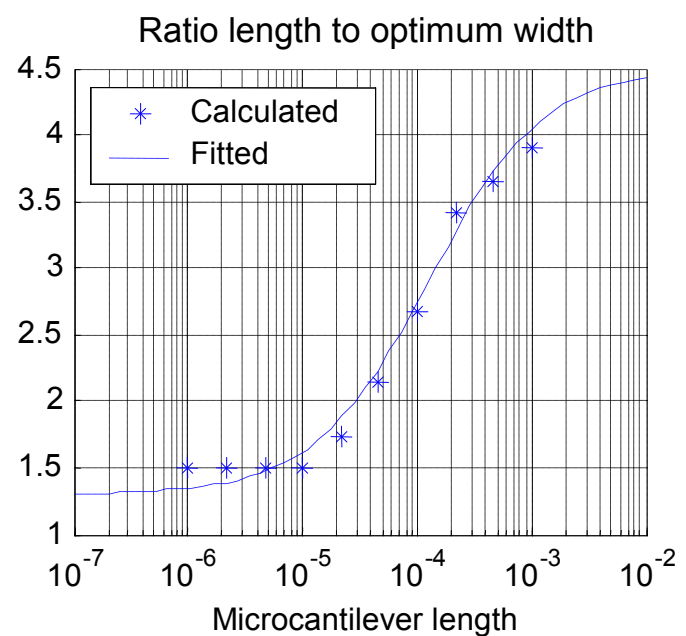

Figure 5: Ratio length to optimum width for different microcantilever lengths (calculated values and fitted model) 
Preprint - Sensors and Actuators B, Vol 118, 2006, pp. 292-296. (doi: 10.1016/j.snb.2006.04.034).

Ratio length to optimum thickness

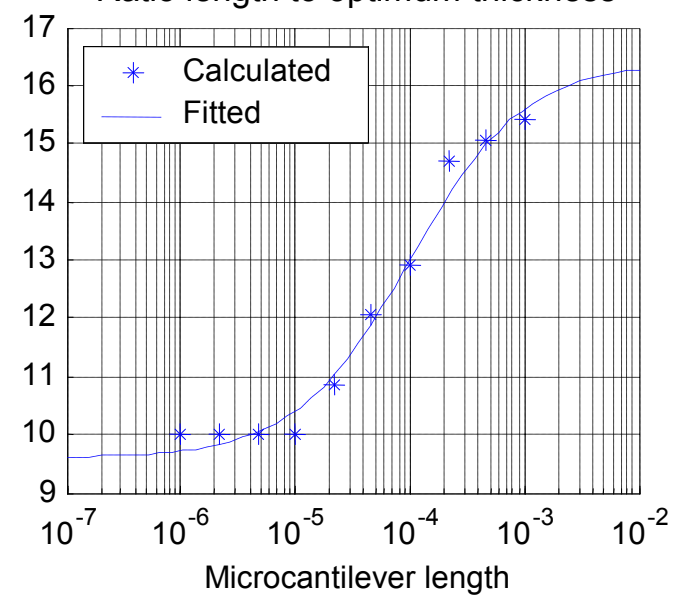

Figure 6: Ratio length to optimum thickness for different microcantilever lengths (calculated values and fitted model) 